\title{
La noción de Justicia Social en la Gaudium et Spes
}

\author{
Claudia Leal \\ FACULTAD DE TEOLOGÍA \\ PONTIFICIA UNIVERSIDAD CATÓLICA DE CHILE
}

"Bajo la luz de Cristo, imagen de Dios invisible, primogénito de toda la creación, el Concilio habla a todos para esclarecer el misterio del hombre y para cooperar en el hallazgo de soluciones que respondan a los principales problemas de nuestra época".

Gaudium et Spes, 10

\section{INTRODUCCIÓN}

En el presente artículo indagaré en la noción de justicia social que encontramos en Gaudium et Spes ${ }^{1}$, ahondando en los temas de ética social que ella misma se encarga de proponer y que, como veremos, corresponden a algunas de las interrogantes fundamentales de la moral social de nuestros días. Se trata en este caso de un documento del magisterio conciliar, que no tiene como fin propio ser un texto de teología moral ni de ética social, por eso nuestra metodología será exegético-analítica.

Si bien la aparición en el documento de los problemas que abordamos está condicionada por las circunstancias históricas, como se puede fácilmente notar, la argumentación conserva su fuerza profética y constituye una excelente herramienta para la reflexión sobre la justicia social. En lugar de construir para este capítulo una estructura temática diversa de la que aparece en la Constitución, he preferido respetar la taxonomía del documento y dejar que el texto dé cuenta de su propia riqueza que, pasados los años, parece adquirir más fuerza y hondura.

En adelante GS. Todas las citas al documento serán tomadas de la edición latínespañol del Concilio Vaticano II, Libreria Editrice Vaticana, Città del Vaticano 1998. 
Contextualicemos brevemente la reflexión que estamos por iniciar recordando que la historia del diálogo entre la iglesia y «el mundo» vivió un momento particular con ocasión de la promulgación de la Constitución GS; en efecto, con dicho documento el Concilio Vaticano II marcó un punto de inflexión en la autocomprensión del lugar y del rol de la Iglesia frente a la sociedad civil, y si bien no se puede hablar de dos Iglesias diversas, una anterior y otra posterior al Concilio, nuestro documento constituye un hito histórico que está lejos de haber agotado su voz no solo en el escenario de la moral social, sino de toda la teología.

Pero la $G S$ no es un documento aislado, y es reconocido unánimemente el eco suscitado por el Concilio Vaticano II en el panorama eclesial. La $G S$ es parte de un conjunto más amplio de documentos magisteriales que comparten una serie de características. Tenemos así que «a juicio de Alberigo y de numerosos historiadores, la novedad conciliar ha de ser indiscutiblemente reconocida en las dos notas de la pastoralidad y de la renovación, que con todo derecho constituirían los rasgos singulares de la inédita propuesta del Vaticano II $»^{2}$. Estas ideas, de "pastoralidad» y de «renovación», adquieren notas propias en el contexto de la teología moral y, más precisamente, en el discurso social de la iglesia de las últimas décadas.

Nuevas exigencias al magisterio eclesial se hacían ya sentir desde los acontecimientos vividos por la humanidad en los últimos años y, progresivamente, el interés y la necesidad se fueron volcando hacia la profundización de una historia de salvación iluminada por el evangelio:

«[... ] el desarrollo doctrinal iniciado por Juan XXIII elevó el magisterio social católico al nivel de la fe, la esperanza y el amor. En el pasado, los papas no mencionaban la revelación bíblica en sus encíclicas sociales, sino que extraían sus argumentos de la filosofía escolástica con la esperanza de que serían comprendidos universalmente. [...] A partir de ahora la visión social de la iglesia se articulará en diálogo con los cambios sociales y a la luz de la Palabra revelada de Dios» ${ }^{3}$.

Son importantes estos antecedentes para entender que por muy singulares que sean las características de la $G S$ en comparación con los otros documentos magisteriales, ella tiene antecedentes en la tradición.

2 M. Vergottini, «Vaticano II: l'evento oltre il testo?», en Teologia 22 (1997) 81-96, 87.

3 G. Baum, «La iglesia: a favor y en contra de la democracia», en Concilium 322 (2007) 557-567, 559. 
Reconocer esta continuidad en el pensamiento social de la iglesia nos ayudará a profundizar nuestra mirada a la hora de enunciar los elementos que, en este documento particular, definen la idea de justicia social. La relevancia de la $G S$ es múltiple, podemos comenzar por señalar que ella constituye el punto de partida para la comprensión del mensaje cristiano no solo como sentimiento compasivo hacia los necesitados, sino también como mensaje que afecta a toda la realidad ${ }^{4}$.

\section{Algunas Claves de lectura}

Aunque ya hemos apuntado que es imprescindible situar la $G S$ en el conjunto de los documentos conciliares, vale la pena señalarlo nuevamente por razones eclesiológicas que una lectura atenta debe tener en cuenta. Recordemos sumariamente, entonces, que «lo que viene rechazado en el texto de la Lumen Gentium es implícitamente rechazado en la $G S$, es decir, el concepto de la iglesia como sociedad perfecta, estrechamente jerárquica y con diversos grados de pertenencia»" ${ }^{5}$ y que, al mismo tiempo, el concepto de Iglesia que asume la Lumen Gentium es el que despliega la $G S$ de frente al mundo.

Es nuestra tarea preguntarnos por las consecuencias de estas afirmaciones en el discurso eclesial sobre la justicia y la ética pública; por esto, comenzaremos identificando las claves interpretativas generales de la $G S$ que, posteriormente, nos servirán para organizar nuestro análisis de la presencia temática de la justicia social en el documento.

En opinión del profesor Raphael Gallagher, los primeros diez numerales del documento constituyen una auténtica clave de interpretación del texto en su totalidad ${ }^{6} \mathrm{y}$, a pesar de las dificultades que entraña su

4 Cf. J. Bullón, «Fundamentos teológicos de la Doctrina Social de la Iglesia», en Moralia 28 (2005), 65-90.

5 R. Gallagher, Una morale sociale "alla luce del Vangelo e dell'esperienza umana" (GS 46). M440-06B Secondo Semestre 2006 // 2007, Dispensa per l'uso degli studenti, 3.

6 Cf. R. Gallagher, Una morale sociale "alla luce del Vangelo e dell'esperienza umana" (GS 46). M440-06B Secondo Semestre 2006 // 2007, Dispensa per l'uso degli studenti, 3. Ver también W. McDonough, “New terrain” and a "stumbling stone" in redemptorist contributions to Gaudium et Spes: on relating and juxtaposing truth's formulation and its experience», en Studia Moralia 35 (1997) 9-46, 10, donde «much of the story of the drafting of Gaudium et Spes was one of searching 
exégesis, su importancia para la lectura total no puede ser ignorada ${ }^{7}$. En dichos artículos emergen las ideas-eje de toda la declaración, es decir: el diálogo, la solidaridad y la comprensión histórica del ser humano.

Sobre la idea de diálogo como criterio hermenéutico de la GS no existe mayor discusión, dado que «a partir de la intervención decisiva del Cardinal Suenens del 4 de diciembre del 1962, el entero proyecto toma forma basado en el concepto de "diálogo" " ${ }^{8}$ y dicha decisión se deja sentir con claridad en el trabajo de las comisiones, en los esquemas preparatorios y en el documento final. También sobre la idea de solidaridad encontramos antecedentes que la sitúan como una de las nociones que acompañó buena parte del proceso de redacción de la GS; los padres conciliares deseaban mostrar al mundo que la Iglesia le es cercana y que participa de sus anhelos, de sus éxitos y fracasos.

El documento final está marcado por una declaración de solidaridad por parte de la Iglesia en el sentido de que ninguna de las realidades humanas la deja indiferente, y es esta óptica la que da el ritmo a la Constitución? ${ }^{9}$ No es esta una afirmación sin historia ya que fue necesario superar los temores que entrañaba una posible identificación de la Iglesia con el mundo ${ }^{10}$. Dicha participación de la Iglesia en las alegrías y dolores de cada ser humano no está dictada exclusivamente por razones de justicia, sino por motivos más profundos, que tienen que ver con la voluntad

for an adequate way of speaking about the "pastoral" and the "moral" together; about what this paper will call truth's formulation and its experience».

7 Cf. R. Gallagher, "Change and continuity in the human condition. The implications of GS pars. 4-10 for moral theology», en Studia Moralia 35 (1997) 49-69, 49-50.

8 Cf. R. Gallagher, «Change and continuity in the human condition. The implications of GS pars. 4-10 for moral theology», en Studia Moralia 35 (1997) 50-52. Esta afirmación es confirmada por W. McDonough, "New terrain" and a "stumbling stone" in redemptorist contributions to Gaudium et Spes: on relating and juxtaposing truth's formulation and its experience», en Studia Moralia 35 (1997) 26, donde, teniendo como contexto las afirmaciones de GS en torno a la familia y el matrimonio, señala: «Suenen’s speech reflects a new way of describing the relationship between changeable human experience and the unchangeable law of God».

9 Cf. GS, Proemio.

10 Cf. R. Gallagher, "Change and continuity in the human condition. The implications of GS pars. 4-10 for moral theology», en Studia Moralia 35 (1997) 52 
y el proyecto de Su fundador ${ }^{11}$. Desde $G S$ resulta imposible poner en duda la indisoluble relación entre el ser cristiano y el compromiso con las realidades temporales ${ }^{12}$.

El compromiso solidario con el mundo comporta, primero que todo, una lectura de la realidad humana: «la primera tarea es aquella de comprender, por una parte, "la uniformidad del destino del género humano" y, por otra, de ver los desequilibrios económicos y sociales como efectos de un desequilibrio de otro tipo, del cual la víctima es el hombre mismo» ${ }^{13}$. Esta lectura de la historia humana, sin embargo, no puede ser hecha bajo signos fatalistas, el Vaticano II reconoció la vida laical como un valor ${ }^{14}$ y nos brinda una visión integral del ser humano, una aproximación optimista a la semilla de verdad que yace en lo profundo del corazón humano. Este optimismo se mantiene coherentemente también al tratar los urgentes problemas que empañan la historia humana, porque ninguno de ellos puede cancelar la creciente sensibilidad de frente a la injusticia y la aspiración de una vida más humana, espiritual y materialmente hablando, para todos los miembros de la humanidad ${ }^{15}$.

Este sentido de responsabilidad social da origen a una preocupación en los planos político y económico dado que de ellos depende concretamente el mejoramiento de la calidad de vida de miles de personas.

11 Cf. GS 3.

12 Cf. La interesante reflexión desarrollada en W. McDonough, "New terrain" and a "stumbling stone" in redemptorist contributions to Gaudium et Spes: on relating and juxtaposing truth's formulation and its experience», en Studia Moralia 35 (1997 11, que señala: «Bernhard Haring and Domenico Capone brought St. Alphonsus Liguori's concern that Catholic morality address the practical lives of ordinary people to the center of Gaudium et Spes».

13 A. Ndreca, «La libertà come destino dell'uomo alla luce della Gaudium et Spes», en Euntes Docete 2 (2006),97-105, 98.

14 Cf. G. Piana, "Cristianesimo come "religione civile" ", en Aggiornamenti Sociali 03 (2006) 223-234, 231.

15 S. O'Riordan, "The Second Vatican Council's psychology of personal and social life», en Studia Moralia IV (1966), 173, "The positive psychology of man, of human life and human labour, embodied in the whole of the first part of the Constitution amounts to a definitive exclusion of dualism from the psychological thinking of the Church - that unscriptural dualism, deriving ultimately from Hellenistic psychology, which exalts man's soul or spirit at the expense of his body and regards involvement with the material world by 'servile' labour as a captivity or punishment humiliation of the sovereign and transcendent spirit». Cf. GS 3, 9. 
«El desarrollo es posible solo si se apoya sobre una base moral que reconozca la importancia de la dignidad humana (nótese la recurrencia de esta idea en el texto) en un contexto comunitario. El artículo 10 toca el nudo central del argumento. Un cambio jamás es una cosa puramente exterior, por lo que no basta hacer una descripción superficial. El cambio necesita de criterios para su evaluación, y el texto apunta caramente a criterios de naturaleza religiosa y ética» ${ }^{16}$.

Por último, como tercera clave de lectura, señalemos que «en la $G S$ "mundo" asume el valor de un término antropológico (en lugar de cosmológico), indica el locus en el cual se desenvuelve el drama de la vida humana ${ }^{17}$. Este lenguaje nos habla de la historicidad de la vida humana, no solo en el sentido tradicional del término sino quizás especialmente refiriéndose a la constitución interna más profunda y central del ser humano ${ }^{18}$. Se trata de un íntimo modo de ser que, desplegándose en el tiempo y en el espacio, convierte la historia en expresión de la libertad fundamental del hombre, "la importancia de la GS está en su modo de entender la verdad de la persona humana en un contexto histórico, esto es: la historia es humanizada por las fuerzas de la justicia, del derecho y de la libertad, porque ellas contribuyen a mejorar la comunidad y las personas» ${ }^{19}$.

\section{LA DIGNIDAD DE LA PERSONA HUMANA (ARTí́culOs 12-22)}

En los discursos éticos actuales la idea de «dignidad» es una de las más difundidas, es casi omnipresente en documentos legislativos, filosóficos, académicos, etc.; no es sin embargo siempre fácil hacerse una idea relativamente precisa de sus contenidos. Nuestro documento, sensible a esta tendencia de las ciencias sociales del siglo XX, también se sirve de la

16 R. Gallagher, Una morale sociale "alla luce del Vangelo e dell'esperienza umana" (GS 46) 8.

17 R. Gallagher, Una morale sociale "alla luce del Vangelo e dell'esperienza umana" (GS 46) 3.

18 «[...] the Constitution assigns a historical character to the integral, dynamic, psychological life of man. A pattern of progress and development emerges from and gives significance to the processes of change that mark this as well as other aspects of his life», S. O'Riordan, "The Second Vatican Council's psychology of personal and social life», en Studia Moralia IV (1966) 174.

19 R. Gallagher, Una morale sociale "alla luce del Vangelo e dell'esperienza umana" (GS 46) 43. 
idea de dignidad para su argumentación y desde luego es menester que consideremos su visión sobre el particular.

En el artículo 9 de la $G S$ se dice que existe «una vida digna del hombre», es decir, una vida que corresponde a su dignidad, caracterizada como "plena y libre», y que al servicio de esta vida debe estar cualquier tipo de bien. En el 41, en tanto, encontramos que la Iglesia reclama su autoridad para poder decir una palabra propia sobre la dignidad humana ${ }^{20}$.

La idea de la dignidad humana en el pensamiento eclesial se fundó en algún momento, por ejemplo en J. Maritain, en el pensamiento de Santo Tomás. Luego, el magisterio fue más allá, apoyándose solo en la razón gracias a la doctrina de la distinción entre los órdenes natural y sobrenatural. En Pacem in Terris Juan XXIII, por su parte, aduce también argumentos desde la Escritura ${ }^{21}$. La raíz última y fundamental de la dignidad humana, para $G S$, está en la interioridad del hombre ${ }^{22}$.

Una veta de reflexión importante para nosotros son los nexos entre esta comprensión de la dignidad humana y el discurso sobre los derechos. "La enseñanza del Concilio sobre los derechos del hombre se fun$\mathrm{da}$ en la dignidad de la persona, cuyas exigencias devienen plenamente manifiestas a la razón humana a través de la experiencia de la historia; al mismo tiempo, esto funda sus raíces en la revelación divina $»^{23}$. Sobre esta base la GS instaura la correspondencia entre cristianismo e iluminismo, tratando de llegar a una conciliación entre Iglesia y modernidad.

La raíz de los derechos consiste en «las estructuras antropológicas fundamentales que constituyen la libertad humana, su relación con la conciencia, en condiciones de igualdad entre los seres humanos y en la mutua ordenación de todas las libertades al bien común» ${ }^{24}$.

20 A. Vendemiati, «Giustizia, responsabilità e verità. Diritti dell' uomo nella Gaudium et Spes e nella Dignitatis Humanae», en Euntes Docete 2 (2006) 81-96, 84-85.

21 Cf. G. BAum, «La iglesia: a favor y en contra de la democracia», en Concilium 322 (2007) 559.

22 Cf. GS 15, 16.

23 A. Vendemiati, «Giustizia, responsabilità e verità. Diritti dell' uomo nella Gaudium et Spes e nella Dignitatis Humanae», en Euntes Docete 2 (2006)86.

24 A. Vendemiati, «Giustizia, responsabilità e verità. Diritti dell' uomo nella Gaudium et Spes ..., 87. 
La $G S$ proporciona una base equilibrada para el discurso acerca de los derechos, situándolos sobre la base del bien común. A partir de tal presupuesto es más fácil recordar que «por muy amplios y articulados que sean los elencos de derechos humanos, por muy solemnes que sean sus promulgaciones, por muy profundas que sean sus fundaciones ético jurídicas, ellos están destinados a permanecer inoperantes si no se reconocen los deberes correspondientes ${ }^{25}$.

La idea de diálogo al interno de la $G S$, de la que ya hemos hablado como clave de lectura, se pone en movimiento poniendo al centro de la preocupación la persona humana, no se trata aquí de un diálogo con objetivos doctrinales. En el artículo 12 vemos una búsqueda por dar con una visión equilibrada del ser humano, ni pesimista ni ingenuamente optimista. En este y en los siguientes números hay una riqueza antropológica importante, la opción del concilio es, diríamos, fenomenológica; más importante que indagar en el origen y en la naturaleza del mal, la muerte, el ateísmo, etc., es procurar hacernos cargo de ellos con medios que nos humanicen ${ }^{26}$.

En el artículo 16 el reconocimiento de la inquebrantable dignidad de la conciencia, aun de aquella que yerra por ignorancia invencible, consagra la interioridad como fundamento de la dignidad humana y la fidelidad a ella como el mejor medio para construir una sociedad más justa ${ }^{27}$.

25 A. Vendemiati, «Giustizia, responsabilità e verità. Diritti dell' uomo nella Gaudium et Spes ... , 81. Citando a J. RatZinger, «Ragione e fede. Scambio reciproco per un'etica comune», en J. Habermas, Ragione e fede in dialogo (Marsilio, Padova 2005) 76.

26 Cf. R. Gallagher, Una morale sociale "alla luce del Vangelo e dell'esperienza umana" (GS 46) ..., 12. «El texto evita cualquier terminología neoescolástica que se refiera a la idea de natura, praeter-natura y super-natura, porque lo que urge es ofrecer una interpretación [...] que consienta el diálogo más amplio posible».

27 «En cualquier manera que se interprete este artículo, dos puntos deben quedar fuera de discusión: la conciencia es una realidad objetiva y trascendente. El artículo rechaza cualquier falso individualismo, ética de la situación, o racionalismo", R. Gallagher, Una morale sociale "alla luce del Vangelo e dell'esperienza umana" (GS 46) ..., 12. Sobre la influencia de D. Capone en la redacción definitiva de GS 16 ver W. McDonough, "New terrain" and a "stumbling stone" in redemptorist contributions to Gaudium et Spes: on relating and juxtaposing truth's formulation and its experience», en Studia Moralia 35 (1997) 12 y ss., así como la bibliografía señalada en dicho artículo. 
Podemos concluir este breve análisis de la idea de dignidad humana en la GS señalando con Baum:

«[...] puesto que la alta dignidad de los seres humanos, en la que se fundamenta la teoría democrática católica, no es solamente una conclusión metafísica, sino también (...) una verdad revelada en la Escritura, la promoción de los derechos humanos y de la subjetividad democrática forma parte de la misión evangelizadora de la Iglesia" " ${ }^{28}$.

\section{Una COMUnidad de personas (artículos 23-32)}

Si bien una lectura atenta de la GS y de los documentos de la Doctrina Social de la Iglesia en general, permitirá reconocer en ella elementos liberales y diversos argumentos que nos permiten sostener la presencia de ideas cercanas al contractualismo, la intención que le sirve de fondo es afirmar la sociabilidad de los seres humanos como un don, y no como una conde$n^{29}$. A lo largo de nuestra investigación, emerge ya que de la elección que hagamos colectivamente en este sentido, es decir de como entendamos la socialidad humana, depende mucho de lo que podamos decir a posteriori sobre la justicia social. Es lo que queremos enfatizar en este apartado.

La convicción acerca de la profunda interdependencia que une a todos los seres humanos, independientemente de su origen o condición, es el gran anuncio del segundo capítulo de la GS; cada uno de los artículos insiste en el hecho de que, por una parte, el bien de la familia humana depende de un delicado equilibrio entre el individuo y la sociedad y, por otra, en que el orden social debe estar al servicio de la persona y no al revés. Esta tensión entre el individuo y la sociedad no puede ser artificialmente resuelta, sino más bien puesta al servicio de las vocaciones más profundas de los seres humanos, vistos individualmente y como fines en sí mismos.

28 G. BAUM, «La iglesia: a favor y en contra de la democracia», en Concilium 322 (2007) 560 .

29 «Dios no crea, ni quiere salvar a los hombres singularmente sino en comunidad, como familia de hermanos. Dios une en el comienzo -crea al ser humano en comunión-. Todos los seres humanos se encuentran pues unidos en Dios, en su voluntad salvífica. El ser humano en cuanto ser comunitario está en la voluntad de Dios que origina al género humano en igualdad y le orienta igualmente a una vida en plenitud: El origina la unión, la mantiene y la culmina», J. Bullón, «Fundamentos teológicos de la Doctrina Social de la Iglesia», en Moralia 28 (2005) 80-81. 
El artículo 24 es una tentativa relativamente exitosa de analizar la base teológica de la naturaleza social de cada individuo. Es exitosa especialmente por la antropología que le sirve de base y también por el constraste que ella refleja frente a aquellas antropologías contractualistas que sirven como fundamento a las teorías éticas propias de la modernidad, donde la dimensión de la vida humana en comunidad es pensada casi como una condena necesaria.

Pero aún se puede ahondar más en la razón teológica de la vida comunitaria: Dios en su vida trinitaria es el fundamento y razón de la misma. La dimensión comunitaria de la existencia adquiere una perspectiva nueva desde el Dios Trino. Dios es Dios no en cuanto que aparece encerrado en su misterio impenetrable; nuestro Dios, aunque misterio insondable, se nos ha ido develando en la historia y así hemos podido ir entendiendo lo que es en sí y para nosotros. La GS nos dice: «hay una cierta semejanza entre la unión de las personas divinas y la de los hijos de Dios en la verdad y en el amor ${ }^{30}$. Se relaciona, pues, la naturaleza social de la persona humana con el misterio de la Trinidad y desde Ella se comprende la dimensión comunitaria de la existencia humana ${ }^{31}$.

El artículo 25 es importantísimo. Una lectura superficial podría sugerir la existencia de una división entre la persona humana en cuanto individuo aislado y la persona como parte de la sociedad. Pero una mirada exhaustiva al texto demuestra que lo que el Concilio desea es destacar el hecho que la persona humana es social en su constitución ${ }^{32}$.

¿Cómo proyectar estas afirmaciones al campo de la justicia social? Para comenzar, diciendo que si la persona es comprendida como un ser social desde su origen, las estructuras no pueden ser consideradas un agregado secundario, ellas son importantes y de ellas depende, en

30 GS 24 .

31 Cf. J. Bullón, «Fundamentos teológicos de la Doctrina Social de la Iglesia», en Moralia 28 (2005) 81.

32 Cf. R. O'Riordan, "The Second Vatican Council's psychology of personal and social life», en Studia Moralia, 171, "The Council's pastoral answers to these questions mingle theological, philosophical and psychological elements in a composite whole. All these elements do in any case merge into each other: no rigid lines of division can be established between them. They have to be seen, not as distinct entities brought together by an external unifying force, but as different aspects of the one reality - man in his concrete existence, individual and social». 
buena medida, que la vocación social de los hombres y mujeres pueda desplegarse significativa y positivamente ${ }^{33}$. Comprender de esta manera la vocación social del ser humano significa confiar en que, como comunidad moral, somos capaces de superar la desconfianza recíproca y de crear instituciones democráticas y justas.

El artículo 26 de la GS se expresa positivamente sobre los derechos de las personas hablando de 'las necesidades y las legítimas aspiraciones' de individuos y grupos en el marco de la interdependencia siempre más estrecha entre los seres humanos ${ }^{34}$. Un elenco de estas aspiraciones se va construyendo a lo largo de este capítulo y vale la pena destacar la incipiente sensibilidad de género que ya se venía insinuando a lo largo del documento en más de un artículo, que aquí aparece una vez más y que, a lo largo de la declaración, va tomando una forma más definida sin dejar de ser tímida. En general, esta naciente sensibilidad se traduce en el reconocimiento, por parte del Concilio, de las aspiraciones de igualdad que las mujeres comienzan a manifestar públicamente por medio de diversos movimientos sociales, y adquiere su mayor vigor en el artículo 29, donde sirve para ejemplificar los casos genéricos de discriminación en los derechos fundamentales de las personas que enumera previamente. El texto, una vez más a propósito de este particular, se muestra consciente de las luces y oscuridades de la realidad humana y busca el justo equilibrio entre la afirmación del individuo, y de la comunidad ${ }^{35}$.

Incluso cuando la $G S$ reconoce y valora los movimientos sociales de reivindicación gracias a los cuales las demandas de justicia de los sectores oprimidos se hacen escuchar en la sociedad, ella «pone el acento en la interioridad de la persona, como lugar de encuentro del individuo con

33 Cf. R. Gallagher, Una morale sociale "alla luce del Vangelo e dell'esperienza umana" (GS 46) ..., 17.

34 Cf. A. Vendemiati, «Giustizia, responsabilità e verità. Diritti dell'uomo nella Gaudium et Spes e nella Dignitatis Humanae», en Euntes Docete 2 (2006)83.

35 Cf. S. O'Riordan, "The Second Vatican Council's psychology of personal and social life», en Studia Moralia IV (1966), 170. "This nucleus of theological anthropology contained in the document and undoubtedly destined to provoke further doctrinal work in the same sphere implies also a fresh and constructive philosophy of man. In fact the Constitution borrows many points explicitly from modern philosophies of existence and of personalism, weaving them into the texture of its pastoral theology. Accompanying all this and interwoven with it we find a distinctive psychology of personal and social life». 
su Creador y como la única voz que combate el conformismo del mundo exterior, distinguiendo así el individuo de la masa $»^{36}$.

Precisemos una vez más el sentido de la propuesta de diálogo en nuestro documento, esta vez con ocasión de las referencias a la socialidad como dimensión constitutiva de los seres humanos y de las consecuencias que esta afirmación conlleva en la esfera social:

«[...] es de notar como el texto demuestra que el hecho de entrar en diálogo no significa ni conlleva una forma de indiferentismo moral: el respeto de la libertad y la intención cargada de amor se oponen radicalmente a una tal posibilidad [...] el deseo de diálogo evita cualquier indiferentismo y dogmatismo por una simple razón: en el diálogo la plenitud de la verdad se alza delante de nuestros ojos y es, por lo tanto, buscada, no se encuentra a nuestras espaldas como si fuera nuestra posesión personal" " ${ }^{37}$.

El artículo 31, lúcidamente señala la educación y la vida cultural como las herramientas fundamentales contra la indiferencia ética y como medios privilegiados en el fomento de la responsabilidad y de la participación ciudadana en la vida pública.

\section{LA MISIÓN DE LA IGLESIA EN EL MUNDO (ARTí́cULOS 40-45)}

La misión eclesial por antonomasia es la de anunciar la Buena Nueva de Jesucristo a todos los hombres y mujeres del mundo, y una de las dimensiones de ese anuncio es la que tiene que ver con las consecuencias éticas del mensaje de salvación. Por eso ni la Iglesia, como institución, ni los cristianos pueden sustraerse de tomar parte en las "cuestiones sociales", convicción que el el último siglo fue sistematizada magisterialmente.

«Este breve capítulo explica la doble base de la misión de la Iglesia en el mundo: por una parte teológica, por otra cristológica. La base teológica está claramente relacionada con el objetivo universal de la creación, así como viene explicado en el Antiguo Testamento; la base

36 A. Ndreca, "La libertà come destino dell'uomo alla luce della Gaudium et Spes», en Euntes Docete 2 (2006) 99.

37 R. Gallagher, Una morale sociale "alla luce del Vangelo e dell'esperienza umana" (GS 46) ..., 18. 
cristológica, en cambio, está claramente colegada al objetivo universal de salvación como viene comprendido en el Nuevo Testamento» ${ }^{38}$.

Las consecuencias que se derivan de estas afirmaciones son profundas, especialmente para la teología moral social que, a partir de ellas debe asumir su propio deber para con el mundo, el de acompañar la historia humana como historia de salvación:

«[...] podemos dar por terminados los contrastes entre Iglesia y estado, del mismo modo en que ha terminado el combate entre un tipo de autoridad y otro. La perspectiva que nuestro texto ofrece es una perspectiva de fe en la historia, en el evangelio y en la cultura. El artículo 42 demuestra que este mundo posee un valor y una autonomía propios y no se limita a ser solo una etapa del camino hacia el verdadero mundo en el cielo» ${ }^{39}$.

En el artículo 43 hay interesantes notas sobre la Iglesia que el Concilio desea, de especial interés son aquellas que nos hablan de una Iglesia en camino que con humildad busca mantenerse fiel al espíritu que su Esposo le ha transmitido. Lejana del sentirse dueña de la verdad, es en suma, una Iglesia, donde el desacuerdo es posible porque diversas son las formas y contextos en que los cristianos tratan de vivir cada día el evangelio y porque cada uno de sus hijos está en proceso de renovación y purificación.

La tarea encomendada a la Iglesia en medio de las realidades temporales puede ser comprendida en diversas maneras, cada una de ellas representativa de una sensibilidad eclesial que complementa a las demás y que no está exenta de crítica. En este sentido, algunos autores ven como un retroceso la encíclica Deus caritas est, porque «restringe la misión social de la Iglesia a la caridad y el servicio, y advierte del peligro de interpretar esta misión como un desafío al orden político de la sociedad ${ }^{40}$.

La apertura del Concilio en lo que respecta al discurso social alcanza un clímax importante con la afirmación sobre lo que ella recibe del mundo: «el título del artículo 44 muestra ya la profundidad de su aserto:

38 R. Gallagher, Una morale sociale "alla luce del Vangelo e dell'esperienza umana" (GS 46) ..., 26.

39 R. Gallagher, Una morale sociale "alla luce del Vangelo e dell'esperienza umana" (GS 46) ..., 27.

40 G. BAum, «La iglesia: a favor y en contra de la democracia», en Concilium 322 (2007) 565. 
de adiutorio quod Ecclesia a mundo hodierno accipit. El Concilio no se limita a enumerar los elementos de pecado al interior de la Iglesia, dice también que la Iglesia puede aprender del mundo $»^{41}$.

Una última acotación debe ser hecha para destacar el aporte de la $G S$ en relación al fortalecimiento de los principios democráticos que cada día necesitan con más urgencia de protección y estímulo: «el Concilio fue inteligentemente consciente de que la Iglesia no honraba el principio de subsidiariedad que formaba parte de su propio magisterio social. (Así,) el Concilio recomendaba un ejercicio de la autoridad que requería un diálogo previo a través de las instituciones reconocidas» ${ }^{42}$.

\section{El matrimonio y la familia (artículos 46-52)}

Este parágrafo es quizás uno de los más significativos del concilio y, seguramente, uno de aquellos con la historia más difícil, como lo testimonian sus numerosos comentadores ${ }^{43}$. El cambio desde una visión jurídico moral a una sacramental del matrimonio ha sido uno de los aspectos del Concilio Vaticano II que, seguramente, tuvo mayores repercusiones en la vida de los creyentes y, al mismo tiempo, uno de los que más exige de parte de la teología moral.

Este giro en el lenguaje y en los conceptos que servían como base a la teología del matrimonio es del todo coherente con las afirmaciones que hasta este punto la Constitución ha hecho, especialmente aquellas que tienen que ver con la historicidad como una nota dramática, negativa y positiva al mismo tiempo, de la existencia humana. Es natural que los padres conciliares no nos den una definición explícita de lo que debemos entender por experiencia, término que se repite constantemente a lo largo del discurso y que será más y más importante en la reflexión teológica postconciliar.

41 R. Gallagher, Una morale sociale "alla luce del Vangelo e dell'esperienza umana" (GS 46) ..., 29.

42 G. Baum, «La Iglesia: a favor y en contra de la democracia», en Concilium 322 (2007) 566.

43 Cf. W. McDonough, "New terrain" and a "stumbling stone" in redemptorist contributions to Gaudium et Spes: on relating and juxtaposing truth's formulation and its experience», en Studia Moralia 35 (1997) 9-48, 21 y ss. 
Cuando hablamos de un giro linguístico nos referimos a que «el cambio desde el lenguaje contractual al lenguaje de alianza tiene una importancia fundamental», ${ }^{44}$ porque instala las bases para modificar la jerarquía de los bienes del matrimonio según las coordenadas de la nueva filosofía personalista y, de esta manera, afirmar que el matrimonio y la familia miran al bien de sus miembros, y no al revés ${ }^{45}$. La "comunión total de toda la vida", como historia de un amor que "progresa y va madurando», es la realidad que da sentido a las demás características de la vida de pareja:

«[...] lo que es bendecido por Dios es el amor de alianza de la pareja: no está dado el hecho que El bendiga un "contrato" o la "fertilidad" como tal. Claramente, el amor de alianza es comprendido como un amor abierto a la vida: pero el texto formula deliberadamente el significado del matrimonio en términos de alianza en lugar de buscar explicarlo en términos de efectos colaterales del matrimonio" ${ }^{46}$.

La vida familiar ya no representa en la Iglesia un estado de vida inferior al estado de vida célibe, ella es bendecida por Dios y protegida como un bien con valor en sí mismo; consiste en un estado de vida llamado a una perfección que le es propia, perfección que tiene que ver con la fertilidad de la relación conyugal, pero sobre todo, con el amor y sostén mutuo que sus miembros se donan recíprocamente. Sin abandonar la visión tradicional de familia, la $G S$ no parece estar tan lejos de las actuales propuestas de las ciencias sociales, que ven la familia como el espacio donde los individuos reciben una serie de bienes necesarios para desplegar satisfactoriamente sus vidas, material, psicológica y socialmente hablando.

En el artículo 52 el matrimonio es visto como un asunto social y no solo como una institución relevante para el individuo, se trata de una reflexión auténticamente vanguardista en el contexto de las teorías ético sociales de la modernidad que durante tanto tiempo, y lamentablemen-

44 R. Gallagher, Una morale sociale "alla luce del Vangelo e dell'esperienza umana" (GS 46), ... 32. Sobre los interesantes antecedentes que la formulación de este capítulo tiene en la teología del matrimonio desarrollada previamente por B. HärING, ver W. McDonough, "New terrain" and a "stumbling stone" in redemptorist contributions to Gaudium et Spes: on relating and juxtaposing truth's formulation and its experience», en Studia Moralia 35 (1997) 17 y ss.

45 Cf. GS 50.

46 Gallagher Raphael, Una morale sociale "alla luce del Vangelo e dell'esperienza umana" (GS 46) ..., 32. 
te, consideraron el matrimonio y la familia como instituciones de la esfera privada, sustrayéndolas del examen público y dejando sin protección a sus miembros más frágiles, es decir, las mujeres y los niños ${ }^{47}$.

Sin embargo, en la misma medida que se puede afirmar un verdadero giro copernicano en los numerales que la $G S$ dedica al matrimonio y a la familia, se puede sostener que el magisterio posterior no sigue sus huellas ${ }^{48}$ y que muchos de los desafíos que nacieron desde la reflexión conciliar permanecen en espera de una respuesta que dé sentido a quienes hoy día se empeñan en construir y vivir una familia.

\section{La CUltura (ARTí́culos 53-62)}

Con aquella fascinante lucidez que le era característica y que seguramente nacía de su vasta experiencia como hombre de iglesia,

«Juan XXIII pensaba que para afirmar en la actualidad el carácter de perenne actualidad de la fe, la Iglesia no debe inmunizarse con sospecha y resentimiento ante la cultura contemporánea, sino que ello solo será posible en un diálogo y una apertura que no sea prejuiciosa ${ }^{49}$.

Es este el espíritu que emana del capítulo que la GS dedica al fomento del progreso cultural, en él, los artistas, los científicos, los intelectuales, etc., son reconocidos como hijos de la Iglesia, hijos predilectos con una vocación particular, que también debe ser puesta al servicio de la salvación universal.

Habiendo dicho esto es más fácil darnos cuenta de la relevancia de abordar el tema de la cultura cuando nos ocupamos de la justicia social; veremos que las razones que yacen en la argumentación de la $G S$ no son

47 Es de notar el hecho que solo en las dos últimas décadas las teorías liberales de ética social se han preocupado de corregir este equívoco, al cual debemos hacer frente incluso en los enfoques de justicia más serios del siglo XX; la teoría de las capacidades es, precisamente, un buen ejemplo de cómo la ética liberal tiene el deber de considerar la familia como una institución pública, en relación a la cual el estado tiene una serie de deberes y responsabilidades, cf. capítulo primero del presente estudio.

48 Véase el interesante análisis de tres documentos magisteriales posconciliares en W. McDonough, "New terrain" and a "stumbling stone" in redemptorist contributions ...» 30 y ss.

49 M. Vergottini, «Vaticano II: l'evento oltre il testo?», en Teologia 22 (1997) 88. 
lejanas de las que sistematiza la teoría de las capacidades y que el tema está lejos de ser considerado accesorio en cada caso.

El lenguaje con que la declaración aborda los grandes temas relativos a la cultura es casi análogo al de las grandes declaraciones de derechos del hombre y nos permite argumentar cómodamente sobre el derecho a la instrucción y a la cultura, especialmente en relación al acceso democrático y a la igualdad entre culturas. ${ }^{50}$ Según A. Vendemiati, el razonamiento de $G S 60$, a propósito del «derecho de todos a una cultura humana conforme a la dignidad de la persona» es análogo al de Hans Jonas "potes, ergo debes», donde el poder genera el deber, el deber la responsabilidad, y la responsabilidad la moralidad ${ }^{51}$.

El artículo 59 señala los principios que deben inspirar las políticas públicas relativas a la cultura, defender la persona en la comunidad, promover la libertad humana, aceptar una legítima autonomía al interior de determinados límites, e insistir en el hecho que la promoción de la cultura supera cualquier proyecto político o económico. En un momento en que para buena parte de la población mundial, la instrucción continúa siendo un «bien de lujo», vale la pena pensar seriamente algunas de estas afirmaciones y preguntarnos por la mejor manera de anunciarlas argumentadamente.

En el artículo 62 hay referencias decisivas en relación a las condiciones en que deben desarrollarse las ciencias teológicas; en este sentido, es imprescindible cultivar una actitud de diálogo con las demás ciencias, que haga a todos los buscadores de la verdad partícipes de la misión de la Iglesia, y que nos ayude a comprender la inteligencia humana como un don de Dios. La libertad de quien ejerce la investigación teológica es

50 «El artículo 53, en apertura, hace hincapié en dos argumentos importantes. La cultura es un factor de la vida de cada persona y de la sociedad, y no solo de aquellos que en algún modo se sienten superiores (por ser 'hombres de cultura'). El segundo argumento pone de relieve el aspecto social e histórico de la cultura. Si bien en nuestro texto la argumentación es más bien descriptiva que analítica, contiene implicaciones de largo alcance. No se podrá volver a decir que una cultura es 'superior' a otra, y no se deberá volver a hablar de la 'naturaleza' separándola de su matriz cultural", R. Gallagher, Una morale sociale "alla luce del Vangelo e dell'esperienza umana" (GS 46) ..., 35.

51 Cf. A. Vendemiati, «Giustizia, responsabilità e verità. Diritti dell'uomo nella Gaudium et Spes e nella Dignitatis Humanae», en Euntes Docete 2 (2006) 91. 
declarada una de las condiciones básicas para que las personas dedicadas a dicha tarea puedan llevar a término su propia función.

Debemos preguntarnos sobre el significado de esta libertad que el Concilio reconoce a quienes cultivan las ciencias teológicas y las repercusiones que ella podría tener a la hora de pensar la justicia social. Recordemos que la sensibilidad del Concilio en relación a la cultura tiene un horizonte histórico interesante, y que el proceso de redacción de nuestro documento se explica, entre otros factores, a la luz de una serie de fenómenos sociales que se vivían en los días de su discusión. La GS, más que cualquier otro de los textos del Concilio, constituye la puesta en práctica de la mentalidad que inspira a la Iglesia de aquellos días, es decir, la decisión explícita de ser permeable a los acontecimientos que afectan históricamente a los miembros de la comunidad, y la voluntad de acompañarlos, hombro a hombro, para discernir dicha experiencia a la luz del evangelio. Es este ideal el que debe inspirar la libertad de quienes ejercitan las ciencias teológicas.

\section{La Vida eConómica y SOCial (aRTículos 63-72)}

El Concilio es testigo de los grandes desequilibrios que la economía de mercado está creando en el mundo, él se da cuenta que las consecuencias son de una magnitud tan considerable que el sentido del progreso y del desarrollo está puesto en juego en la tarea que tenemos, como sociedad, de permitir un acceso mínimamente justo a los bienes que garantizan una vida humana digna de ser considerada como tal. Por este motivo, el capítulo que aborda directamente la vida económica está, casi por completo, dedicado a delinear criterios que garanticen un desarrollo económico justo y equitativo para todos los seres humanos. Estos criterios pueden ser sistematizados en diversas formas, cada una de las cuales tendrá ventajas y desventajas, en esta ocasión presentaremos la lectura que ha hecho de ellos el profesor Raphael Gallagher, dado que su perspectiva es, específicamente, la de la moral social.

La argumentación de Gallagher se concentra en tres criterios que, emergiendo del texto, informan la actividad pública económica:

«[...] en primer lugar, sugiero el criterio de "a cada persona según sus necesidades". La palabra "persona" es usada aquí con prudencia: quiero evitar ciertos conceptos simplistas que arriesgan el disminuir la teología moral personalista. Es necesaria una reflexión rigurosa si queremos 
pasar de argumentos basados ex natura a argumentos basados ex persona, un hecho, este, que no siempre viene notado por quien habla de una teología moral personalista en términos demasiado relajados. La ventaja de este primer criterio es que (a) es inclusivo; (b) es aplicable a las realidades de la vida y (c) es teológico, porque las "necesidades" de la gente pueden potencialmente comprender sus necesidades fundamentales de felicidad y de salvación ${ }^{52}$.

El primer criterio que informa la actividad económica en la GS tiene que ver con que la base para las decisiones institucionales son las necesidades reales de las personas, y no los índices de productividad, el producto interno bruto o el ingreso per cápita. El Concilio advierte sobre la ideología de la ciencia económica:

“[...] según la perspectiva de tales economistas, la salvación y la ortodoxia (es de notar el tono religioso) son el producto de una economía organizada en un modo racional: es la 'buena economía' la que se ha convertido en el nuevo dogma de la religión capitalista. Un concepto de estas características debe ser vigorosamente rechazado. Siguiendo el criterio que acabo de proponer, el sufrimiento de los pobres no es entendido como un mal social, sino solo como el resultado (¡el pecado?) de la ineficiencia económica» ${ }^{53}$.

El segundo criterio propuesto por nuestro autor es: "a cada persona como miembro de comunidades significativas» ${ }^{54}$. La socialidad como dimensión constitutiva del ser humano, que ha venido afirmándose sostenidamente en cada uno de los capítulos precedentes, se transforma aquí en un dato para quienes toman las decisiones relacionadas con la vida económica de la sociedad.

En la misma línea que sugiere este segundo criterio propuesto para la regulación ética de la vida económica, recordemos que una de las capacidades que forman parte de la lista sugerida por Nussbaum es la de pertenencia; en razón de esta capacidad, las personas no pueden ser consideradas como parte de una masa difusa e indeterminada, ni como entes meramente receptivos de las políticas de consumo, porque cada

52 A. Vendemiati, «Giustizia, responsabilità e verità. Diritti dell'uomo nella Gaudium et Spes ..., 40.

53 A. Vendemiati, «Giustizia, responsabilità e verità. Diritti dell'uomo nella Gaudium et Spes ..., 40-41.

54 A. Vendemiati, «Giustizia, responsabilità e verità. Diritti dell'uomo nella Gaudium et Spes ... 41. 
una de ellas posee diversas identidades y roles dentro de los diversos grupos o comunidades de los que forma parte, y dichas identidades pueden adoptar una taxonomía, pero no pueden ser cancelados.

Finalmente, el tercer criterio es: «a cada persona, porque es digna de ser tratada según la justicia de Dios».

«El criterio no tiene una gran necesidad de ser justificado [...] pero lo explicito, precisamente en vistas de lo que hemos dicho antes en relación a la necesidad de ser precisos acerca de la "meta" o el "fin" de la justicia social. A causa de la diversidad de perspectivas sobre la justicia social, nos encontraremos desesperadamente perdidos, en el sentido teológico, si no contamos con un método para resolver las diferencias entre puntos de vista divergentes ${ }^{55}$.

Así, el autor anuncia la meta «teológica» de la justicia social, para lo cual vuelve a la dignidad como valor fundante y criterio de decisión; en efecto, si nos encontramos en la necesidad de tener que elegir entre posturas éticas en conflicto, el criterio del teólogo, del cristiano, es la dignidad que posee cada persona, que la hace merecedora de ser tratada según la justicia de Dios.

Podemos afirmar que la $G S$ reconoce la importancia de la ciencia económica en la vida de las personas, pero plantea la exigencia de situarla en un contexto más amplio, donde las decisiones éticas de la vida política se toman teniendo en consideración un conjunto de datos que ofrecen una visión más completa del ser humano ${ }^{56}$.

La intervención del gobierno en la vida de la sociedad se concibe aquí como protección de la creatividad de los ciudadanos y sus organizaciones y como orientación para su interacción y la coorperación recíproca.

55 A. Vendemiati, «Giustizia, responsabilità e verità. Diritti dell'uomo nella Gaudium et Spes ... 42.

56 «El magisterio social católico se ha opuesto siempre a la separación entre la economía y la ética, implícita en lo que el papado denominaba "capitalismo liberal". La producción, el intercambio y la distribución de bienes, de los que depende el bienestar material de la población, constituyen un desafío ético que no puede abandonarse a las leyes del mercado. Los mercados son instituciones útiles para la eficaz distribución de los bienes, pero han de ser orientados por las regulaciones de los gobiernos para que sirvan al bien común de la sociedad. El nuevo magisterio católico sobre la subjetividad de los ciudadanos pone de manifiesto, de forma más dramática, la falta de legitimidad ética del sistema de marcado no regulado», G. BAUM, «La iglesia: a favor y en contra de la democracia», en Concilium 322 (2007) 560. 
De acuerdo con la posición católica, para promover el bien común de la sociedad, los gobiernos necesitan la contribución activa de todos los ciudadanos y la cooperación de sus diversas organizaciones, pero no pueden dejar de asumir la responsabilidad de dirigir la vida social según criterios de justicia ${ }^{57}$.

\section{La COMUNIDAD POLÍ́TICA (ARTí́culos 73-76)}

Los artículos de este breve apartado están impregnados del lenguaje de los derechos y algunos de ellos bien podrían formar parte de una carta constitucional o una declaración de derechos ${ }^{58}$, es importante hacer una adecuada hermenéutica de estos textos que, por una parte, son tan diferentes de lo que hasta aquel momento encontrábamos en el magisterio conciliar y, por otra, usa nociones tomadas desde la sociología, el derecho y las ciencias políticas, entre otras disciplinas.

El argumento da a la $G S$ la oportunidad de profundizar una vez más la tensión entre la persona singularmente considerada, y la comunidad, estableciendo las responsabilidades que hay en juego:

«[...] bajo la supremacía de Dios, cada persona tiene el deber de participar en la sociedad, en vistas a garantizar los niveles mínimos necesarios para que la vida humana florezca. Puesto de esta manera, resulta fácil notar las diferencias existentes entre el personalismo cristiano y el concepto aislado de la persona como individuo privado" $"$.

A través del «bien común», idea central del capítulo, podemos esbozar «la coordinación de los derechos personales con el bien de la comunidad, lo que a su vez permite rechazar tanto la perspectiva individualista como aquella colectivista ${ }^{60}$.

Es de notar el hecho que, en la $G S$, el derecho de propiedad está subordinado al bien común. En efecto, la titularidad de un bien trae

57 Cf. G. Baum, «La iglesia: a favor y en contra de la democracia», en Concilium 322 (2007)560.

58 Cf. GS 73.

59 R. Gallagher, Una morale sociale "alla luce del Vangelo e dell'esperienza umana" (GS 46) ... 45.

60 A. Vendemiati, «Giustizia, responsabilità e verità. Diritti dell'uomo nella Gaudium et Spes ...»89. 
consigo simultáneamente el deber de usar dicho bien en el marco del respeto y la promoción del bien común ${ }^{61}$.

\section{Conclusión}

Al término de este sintético recorrido a través del cual hemos intentado una lectura ético-social de la Constitución Gaudium et Spes, podemos subrayar dos aspectos fundamentales que emergen de la lectura: su contemporaneidad y su tensión histórico salvífica.

El mero hecho de descubrir una serie de preocupaciones comunes al debate actual sobre ética pública y a la $G S$ es un dato que debemos notar, pues nos permite afirmar que la reflexión de la moral social puede intervenir pertinentemente en dicho debate.

Pero lo que podamos decir desde el Vaticano II sobre la justicia social no se basa exclusivamente en esta preocupación convergente con las de las ciencias humanas; para la Iglesia se trata de algo más radical, porque en el acto de cambiar la comprensión que tenía de ella misma, la Iglesia hizo un aporte salvífico al mundo entero, ella se transformó en protagonista del testimonio que pide a cada uno de los cristianos. El contenido de dicho testimonio es complejo y denso de matices, en la $G S$ tiene que ver, entre otras cosas, con una decisión de transformar la experiencia humana en fuente de experiencia de la voluntad salvífica de Dios para los hombres y mujeres del mundo. La justicia social, en el caso de los cristianos, debe ser pensada y practicada desde este presupuesto. Y no se trata de una tarea sencilla.

La Iglesia puede formar parte del esfuerzo por garantizar a todas las personas la posibilidad de construir una vida en coherencia con la voluntad de Dios para sus hijos. La $G S$ constituye un intento serio de parte de la Iglesia por enunciar las vías concretas en que ella puede llevar a cabo esta misión. La propuesta no consiste solo en indicaciones programáticas, sino más bien en una metodología de lectura e interpretación de la historia, tenemos mucho que aprender todavía de ella ${ }^{62}$.

61 Cf. A. Vendemiati, «Giustizia, responsabilità e verità. Diritti dell'uomo nella Gaudium et Spes ... 92.

62 «La metodología de la GS conserva plenamente su validez para nosotros, aunque el mundo del 2007 es bastante diverso de aquel del 1965, porque se trata de una metodología que apoya su interpretación particular en la naturaleza histórica de 
Mediante la $G S$ la Iglesia pone en evidencia que la acción salvífica de Dios no tiene confines y que, al mismo tiempo, ella se pone en juego en cada realidad humana. La salvación es universal y, contemporáneamente, relativa a cada acontecimiento humano ${ }^{63}$, por eso el Concilio se dirige «a todos los que creen en Dios y conservan en el legado de sus tradiciones preciados elementos religiosos y humanos, deseando que el coloquio abierto nos mueva a todos a recibir fielmente los impulsos del Espíritu y a ejecutarlos con ánimo alegre» ${ }^{64}$.

Los textos del Concilio Vaticano II, y la GS en particular, constituyen la tentativa más lograda de la Iglesia Católica de responder a las grandes preguntas del pueblo creyente, y en ellos seguimos apoyando nuestra convicción de que «la propuesta cristiana puede recuperar su incidencia en la realidad social y política, transformándose en conciencia crítica de todos los sistemas y de todas las ideologías históricas, suscitando la espera por el Reino de Dios que ha de venir» ${ }^{65}$.

la Iglesia en el mundo [...] lo que no cambiará es la necesidad de poseer una metodología eclesiológica capaz de adaptar las nuevas tensiones al interno de la historia humana. El contexto eclesial de una teología de la justicia puede ser descrito sumariamente a la luz de quanto se ha dicho. Implica una correlación entre creación y salvación, entre historia y salvación, entre liberación y salvación», A. Vendemiati, "Giustizia, responsabilità e verità. Diritti dell'uomo nella Gaudium et Spes ... 43. Cf. también W. McDonough, "New terrain" and a "stumbling stone" in redemptorist contributions to ...» 38 "What remains a methodological «stumbling stone» for Catholic moral theology today is to describe how we learn about the changeless in the changeable experience of human beings».

63 «La acción de Dios sobre el ser humano no solamente alcanza a quien se hace receptivo de este don y lo acepta en la fe de la comunidad eclesial, sino también a todos los hombres, ya que su obra redentora salva y santifica a todos los seres humanos: todos los hombres son renovados por El. Su acción, pues, es universal y, por ello, todos los hombres han de ser valorados y queridos. No hay en el mundo situación en la que el hombre pueda vivir que sea neutra con relación a la salvación. Dondequiera esté el hombre se encuentra bajo la acción redentora de la gracia divina», J. Bullón, "Fundamentos teológicos de la Doctrina Social de la Iglesia», en Moralia 28 (2005) ... 75.

64 GS 92.

65 G. Piana, "Cristianesimo come "religione civile"», en Aggiornamenti Sociali 03 (2006) 233-234. 
Resumen: Este artículo es una lectura de la Constitución Gaudium et Spes desde la Teología Moral Social. Mediante un análisis de sus principales apartados temáticos intenta poner de manifiesto las particularidades del docuento y sus contenidos éticos fundamentales para mostrar que desde ellos se configura una idea de comunidad política y una matriz programática de la justicia social.

Palabras clave: Teología Moral Social, Gaudium et Spes, justicia, ética pública.

Abstract: This paper is a reading of the Constitution Gaudium et Spes from Social Moral Theology. Through an analysis of its main thematic sections this work tries to highlight the particularities of this document regarding Social Justice and its fundamental ethical content to show that since they set an idea of political community, and an array of social justice program.

Keywords: Social Moral Theology, Gaudium et Spes, justice, public ethics. 